\title{
COVID 19 PANDEMIC: IMPLICATIONS ON HRM AND SUSTAINABILITY IN THE NEW NORMAL
}

\author{
Maurice Adiga ACA \\ Lecturer, Department of Accountancy, Taraba State University, Jalingo \\ ekaisihi@gmail.com \\ Bassey, Emmanuel Ude \\ School of Basic Studies, Taraba State University, Jalingo \\ emmanueludebassey@gmail.com
}

\begin{abstract}
Organizations productivity all over the globe witnessed a dramatic change occasioned bycoronavirus pandemic which has affected HRM and sustainability of organizations. The study main objective was to heighten the relevance of dynamismin human resource management in the Covid-19 pandemic business environment. The survey research design was employed in the study through the aid of electronic questionnaire and the data was analyzed using SPSS (v25), Excel and Minitab 17. The findings of the study showed that to a greater extent, the performance of employees was not much affected by the pandemic as organizations maintained regular working shift in the early breakout of the virus in Nigeria. The study found that the pandemic altered the usual working modalities of organizations and orchestrated the utilization of e-working. On the performance of employees, work-life balance experience and HRs welfare rating, the study found mixed reactions from HR managers and employees indicating satisfactory and unsatisfactory experience. The pandemic crisis has caused several lingering challenges in the business world which requires a dynamic and strategic approach by HR managers to salvage in other to sustain the organizations and maintain the employees. However, the study recommends a more robust $H R$ to develop employees' skills, especially in information technology. The study also recommends a better incentive plan for employees' and also adequate provision of protective gear at the work environment.
\end{abstract}

Keywords: SHRM, HRM, New normal, Covid-19 pandemic, Sustainability, Performance, Work-place balance, Remote working 


\section{Introduction}

The world in 2019 witnessed a downward slope in productivity and output coupled with the redundancy of workforce which has left economiesand businesses in dare need of survival as a result of the global effect of coronavirus (covid-19) pandemic. According to Iza (2020), the pandemic brought about the acceleration of the digitalization processes where companies embrace the digital platforms to enable employees' access and keep their jobs as well as the sustainability of the company.

Scientifically, this study will be considered erroneous if ever asserted to the claim that the battle against the invisible enemy is over, as countries around the world are currently struggling to curtail the re-emergence of the novel coronavirus (COVID-19) variant. Medically, this upsurge is considered to be the second wave of the deadly, dreaded and widespread novel virus (Sars-CoV-2) which was declared a global pandemic by the World Health Organization WHO on March 11, 2020. The pandemic in this context is an assailant to HRs considered to be one of the greatest carnage on mankind in history, as confirmed (COVID-19) cases worldwide have topped 90 million, with nearly two million fatalities, according to the latest data from Johns Hopkins University (JHU) on 11 January 16, 2021. The shock of the COVID-19 pandemic has unprecedentedly ushered the earth into the atmosphere of wild changes, a new world we now find ourselves where we evolve, adapt and introspect or we retrospect, shrink and die. The global economy appears to be experiencing its deepest rescission since 1930, with many countries undergoing a GDP decline of $20 \%$ and a rapid surge of unemployment (OECD, 2020).

Mathematically, modelling has shown that transmission of the outbreak may be stepped down by the lockdown measure introduced by many governments including Nigeria between March and June 2020 as a necessary action to curtail the widespread of the virus. Unfortunately, they have also halted human and business activities in many sectors disrupted education, placed stress on many channels of global connectivity and undermined confidence. The cruelty of the pandemic has altered global normality; both small and large organizations are now exposed to a volatile business environment, forcing corporate leaders to rethink their business strategies and make rapid changes, putting up new policies and sustainable implements to enable their organization to adapt to the new normal and remain competitive in the global market. Any problem happening in the interconnected world encourages organizations of any size to respond and adapt to the change, as well as manage their employees accordingly (Carnevale \& Hatak, 2020). There is no doubt that the disruption and interference of the COVID-19 pandemic have caused many challenges within the business organization at all level, specifically in the effective deployment and management of their HRs which happens to be the targeted casualty of the merciless virus. Today's usual time, each business has its challenges, but they also have one common feature; their success depends on their employees. HR managers can play a key role in an organization's efforts to operate through the COVID-19 crisis (Iza, 2020). HR approaches within the organization should be technologically adaptive to the new normal, while employee's survival as while as performance is placed in the right perspective.

Resources for utilization are finite and limited, but the exploitative capacity is infinite. A loss of sustainability is always the real outcome of limited resources not managed properly. This gives rise to the essentiality and necessity for business firms and entrepreneurs, irrespective 
of their conations to continuously seek out effective ways to optimally harness and manage available resources at their disposal as a strategy for achieving corporate goals and visions.

This study is not eluded of the increasing pressure on global competition faced by both small and large organizations in the $21^{\text {st }}$ century, and the battle over the control of finite resources within the earth space. Employing the most effective and efficient tools for resources management remain the last resort for any organization which seeks sustainability in the future. The knowledge of sustainable resources management is important and relevant not just to the manufacturing industry but also to a service industry that employs various resources at a different level of the organization to enable them to attain corporate objectives. Without resources, most especially the HRs no business firm or company can operate functionally.

Coronavirus has brought about an uncertain business environment and many companies have been taken unawares with less or no preparation to operate in the new normal. This is the plight of HR managers to develop and initiate strategic forms to manage employees and resources effectively enough to sustain the organizations during and after the pandemic crisis.

Now, considering the sensitive nature of HR and the need for sustainability, this study seeks to make findings on the impact and implication of the COVID-19 pandemic on business organization, and how best performance among employees (HRs) can be optimized and sustained by both small and large organizations particularly in the post-covid-19 era known as the new-normal. Effective management and deployment of the available HRs while adhering to the new way of work-life triggered by the emergence of the novel coronavirus (COVID-19) pandemic, has become an inevitable strategy for corporate organizations who desire economic and business continuity.

\section{The objective of the study}

Taking into consideration the increasing demand for optimal utilization and management of organizational resources specifically the HRs. The primary objective of this study is to heighten the relevance of strategic human resource management in the Covid19 pandemic business environment. Specifically, to

i. $\quad$ Evaluate HRM and employee performance in the new normal

ii. Examine HRM and the work-life balance

iii. Identify inherent challenges confronting organizations in the pandemic crisis

\section{Conceptual Framework}

Human Resource Management is described as a strategic, integrated and coherent approach to employment, development and well-being of the people working in organizations. It has a strong conceptual basis drawn from the behavioural sciences and strategic management, human capital and industrial relations theories. One of the primary features of strategic HRM is its close alignment with business strategy (Dhruba Kumar, 2015). In the study of strategic management, you will discover that there is integration between the firm's business strategy and HR strategies. This linear integration usually results in higher organizational performance. Guest (1989) argues that the key policy goal of (HRM) is to ensure that it is 
fully integrated into strategic planning. This implies that management executives must begin to perceive SHRM as an integrated part of the organization.

HRM has broad practices which include pay and benefits, recruitment and selection, training and development, employee communication, equal employment and labour relation. These HRM practices should be integrated into the organization as a strategy for utilizing and managing the HRs within the organization, thereby achieving organizational excellence. Every organization is composed of key functional units like accounting, marketing, and finance. The HRM is central to the performance of these functional units of the organization. Legge (1995) argues that HRs is valuable and source of competitive advantage and thus they should be topped most effectively and mutually consistent policies that promote commitment. Works of literature reveal that HRM practices can help to create a source of strategic competitive advantage for companies, especially when such practices are aligned with the firm's business strategy. HRM practices are configured to the success of any organization. Being this critical to organizational survival, HRM practices should be integrated as a strategy used to the advantage of the organization. According to lengick-hall (1988), as cited by Glonbler (1993), it is desirable to integrate HRM with the company strategy because integration provides a broader range of solutions for solving the complex organizational problem, and most importantly integration ensures that human, financial and technological resources are considered setting goals and assessing implementation capacities.

To successfully contextualize strategic HRM into the firm's business strategy, this study suggests that firms adopt the system approach. GurhanUysal (2014) American scholars identify SHRM with system approach which tends to increase individual performance in organizations, and it also increases the firm's performance. When an organization is systematically structured it becomes easy to identify the place of SHRM in the organization, attracting greater attention of the management more than it is currently. With the system approach, the HRM will be able to play an interrelated and interdependent role in the entire management structure. HRM should be considered as a subsystem, departmentalized to contribute to the broad objectives of the system as a whole. In the most general sense, a system means a configuration of part connected and joined together by a web of relationship. Von Bertelenffy (1968) defined system as elements in a standing relationship. The elementary relationship is that which exit between SHRM and the firm's business strategy.

The practice of strategic and sustainable human resource management can be traced throughout the progression of civilization. The root of human resource management is as old as science and society. Maybe it was not termed "human resource management" but this pragmatic has always been the key to those who succeeded in all facets of human endeavours in the past and present. Revolutionarily, resources management was the strategic drive during the "Industrial Revolution" the transition of new manufacturing processes in Europe and the United States, during the formative period of (1760). This strategic drive gave waves to global industrial exploration, leading to sustainable growth and development by national and international economies who were involved in this revolution. And those who did not are still paying for it as they struggle with interim economic challenges. HR is an invaluable resource in an organization, scholars argue the $14^{\text {th }}$ Industrial Revolution (IR) and human resource management relation. This opines that the management of HRs was part of the notion and agenda that stemmed the industrial revolution. Therefore, corporate organizations must 
perceive HRM as imperative and fundamental to their performance and presence in the corporate world.

Sustainable resource management is often defined as the planning and decision-making process that seeks to organize and balance the social, economic and environmental demands on resources used to achieve future sustainable benefit (Mohammed, 2016). Resources management is a pragmatic strategy employable by entrepreneurs, government agencies, and business firms, whose goals include profit and stakeholder's maximization, continuity in business, sustainable growth and development of the organization profitability in a competitive environment. Resources for utilization are finite and limited, but the exploitative capacity is infinite. A loss of sustainability is always the real outcome of limited resources not managed properly. This gives rise to the essentiality and necessity for business firms and entrepreneurs, irrespective of their conations to continuously seek out effective ways to optimally harness and management available resources at their disposal as a strategy for achieving corporate goals and visions.

\section{Human Resource Management and Employee effectiveness in the new normal (Post Covid-19)}

COVID-19's impacts on workers and workplaces across the globe have been vehemently dramatic as well as traumatic for industry operators. The worldwide lockdown of businesses and industries that were implemented and mandated to curb the spread of the virus generated a wide array of unique and fundamental challenges for both employees and employers across the globe (Kevin, M. 2020). During the first wave of the deadly virus, socio-economic activities came to a halt. After the gradual reopening of the world economies in the postcovid19 era, normalcy has been altered by the gruesome pandemic of all time. Suddenly we find ourselves in a new world that request new hubs of strategies and skills to thrive and survive corporately and individually.

HRs are no doubt left out of this global cycle of dramatic changes but are challenged to rise to the oddities imposed by the pandemic through new waves of innovative and creative approaches to maintain organizational effectiveness amid the global crisis. One way they can do this is through technological adaptation which is proven to be more effective in the new normal. Organizational leaders are charge to come up with sophisticated HR training and technological advancement programs to leverage the current crisis facing their organizations at a different level. While employees are encouraged to rethink in new ways and approach their roles with a high sense of productivity and effectiveness even as the majority of them work remotely or from home to ensure organizational harmony in the new business environment.

\section{Human Resource Management and Remote working (Work-life balance)}

The COVID-19 pandemic has thrust organizations into high-stress remote working situations. This reactive state does not accurately represent normal remote working. Leadership should not form strong opinions about alternative workplace strategies based on this unprecedented experience (NKF, 2020). Before now, remote working has been viewed with scepticism by employers, but this practice is gradually becoming the standard for organizational sustainability in the new normal. One of the core roles of the HR manager is the measurement 
and evaluation of work performance; remote working or working from home has therefore rendered this core function almost impossible and unrealistic in the new normal. How can organizations monitor their employees working from home? This gap will no doubt devour the general productivity of organizations currently adopting the remote working policy.

Strained challenges seem to be spontaneously inherent with the remote working policy which is perceived to be the new normal even after the Covid-19 pandemic. Small organizations that are not technically and structurally equipped will find it difficult to fully incorporate remote working as a new work-life experience.

\section{Perceived challenges confronting Human resource management in the new normal}

COVID19 is not only a pandemic with widespread impact, it is dramatically changing the way we view and approach different aspects of our lives, businesses and economic order. In the aspect of organizational HRM in the newnormal, we are seeing unprecedented changes that are perceived to have a high negative impact on the core practice of HRM within the organization's and also in business operation. Moreover, Covid19 will impact profoundly on employment and can cause career shock for people (Akkermans, Richardson \&Kraimer, 2020).The pandemic has posed great challenges that are describable as gruesome to the advancement of both human and economic livelihood. The virus is a potential threat to organizational sustainability and human resource management HRM in the new world.

This study was able to identify some of the greatest challenges confronting HRM within the business organization in the new normal ranging from loss of jobs, salary reduction, the prevailing absence of performance measurement and that of workplace connectivity.

\section{Implements for sustainable strategic HRM in the new normal}

The shift into the new normal has already taken place, the question now is how can business organization adapt and thrive sustainably and profitably in the new business world? The virus although has saturated the earth, but remain invisible. Organizations that are determined to remain resilient to the shock, rather than stay stagnant amid the pandemic should therefore respond with a workplace Covid-19 plan as a strategy that will guide them through the plight.

The workplace COVID-19 response plan for business organizations should have the following features:

- Covid-19 prevention measure

- Disinfecting the workplace regularly

- Ensuring sufficient supplies of appropriate masks, alcohol wipes gloves, disinfectant etc.

- A Mechanism for determining if employees, suppliers and customers will be allowed to access the workplace.

- Rehabilitation for sick employees returning to the workplace

- Know where your employees are and where they have been

- Keep up-to-date with accurate information

- Communication strategies; communicate with your employees. 
- Upgrade worker's professional skills, teaching them the needed skills for remote working.

- Allow flexible working hours from work or remote working.

\section{Methodology}

The study adopted the survey design. A questionnaire was developed using google form and distributed HR's personnel and employees via LinkedIn, Email, WhatsApp and Facebook within Nigeria. The questions were open and closed-ended to allow respondents to give unbiased and elaborate responses to the questions. 20 organizations were reachedcovering the six (6) geopolitical zones of Nigeria. $19 \mathrm{HR}$ managers and 215 employees of both public and private organizations participated in the study. The sample size is 234 and the confidence level at $95 \%$.

The data were analyzed using SPSS (v25), Excel and Minitab 17.The results of data analysis measured implication of the pandemic on employees and organizational response to the challenges caused by the pandemic, as well as on modifications in the HRM systems, and strategic HRM. (Adopted and modified from Iza, 2020).

\section{Data Visualization/Analysis}

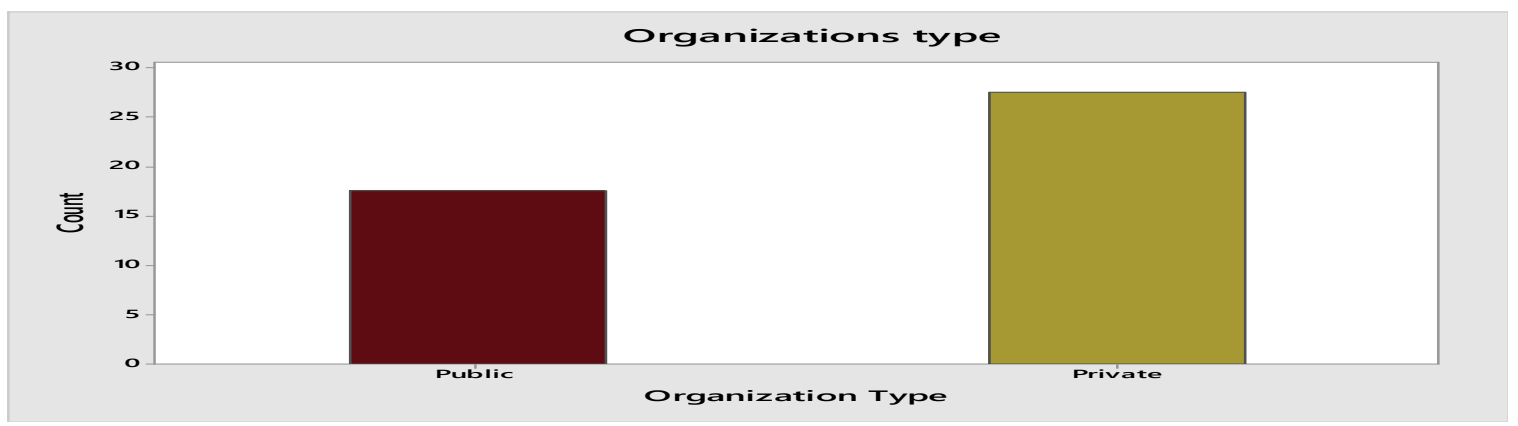

\section{Figure 1:Organization type}

The respondents cut across the public and private sectors of the economy to allow generalizable conclusions which will guide executive boards/top management in its approach to HRs and employees during the pandemic and post-pandemic. $38.9 \%$ of respondents were captured from public organizations while $61.1 \%$ were respondents from profit-oriented organizations (Figure 1).

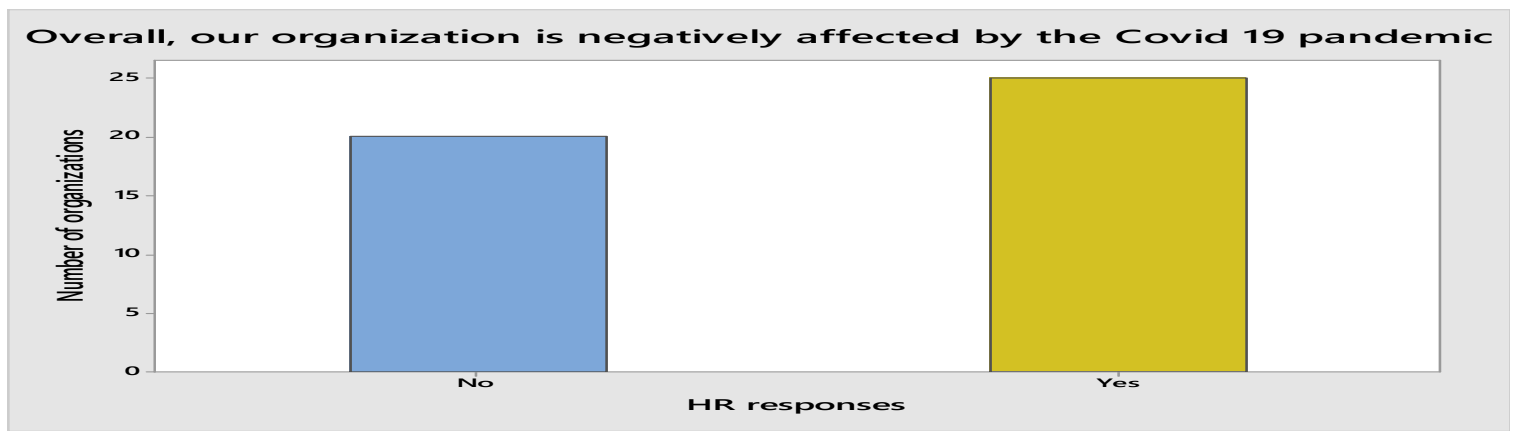

Figure 2: Effect of Covid-19 pandemic on organization 
The pandemic has caused a change in the mode of operation among organizations both in the public and private sector. Owing to its means of infection and fast spread, organizations require a different approach from the usual to curtail the spread. The respondents (Figure 2) spanning from all the economic sectors, manufacturing, agriculture, financial services, ICT, Health, Education and others indicate the varying effect on the Covid-19 pandemic on its operations. $44.44 \%$ experienced no direct effect of the pandemic crisis on its business operations while $55.56 \%$ indicate a severe impact on its business operation. The No effect responses emanated from the ICT sector that still could operate about $80 \%$ due to its nature of services which could be handled remotely. More also, responses from the ICT sector showed a rise in patronage as other companies were forced to adjusted and utilized ICT in initiating remote working.

The executive board/top management has communicated adequately to the employees about the pandemic

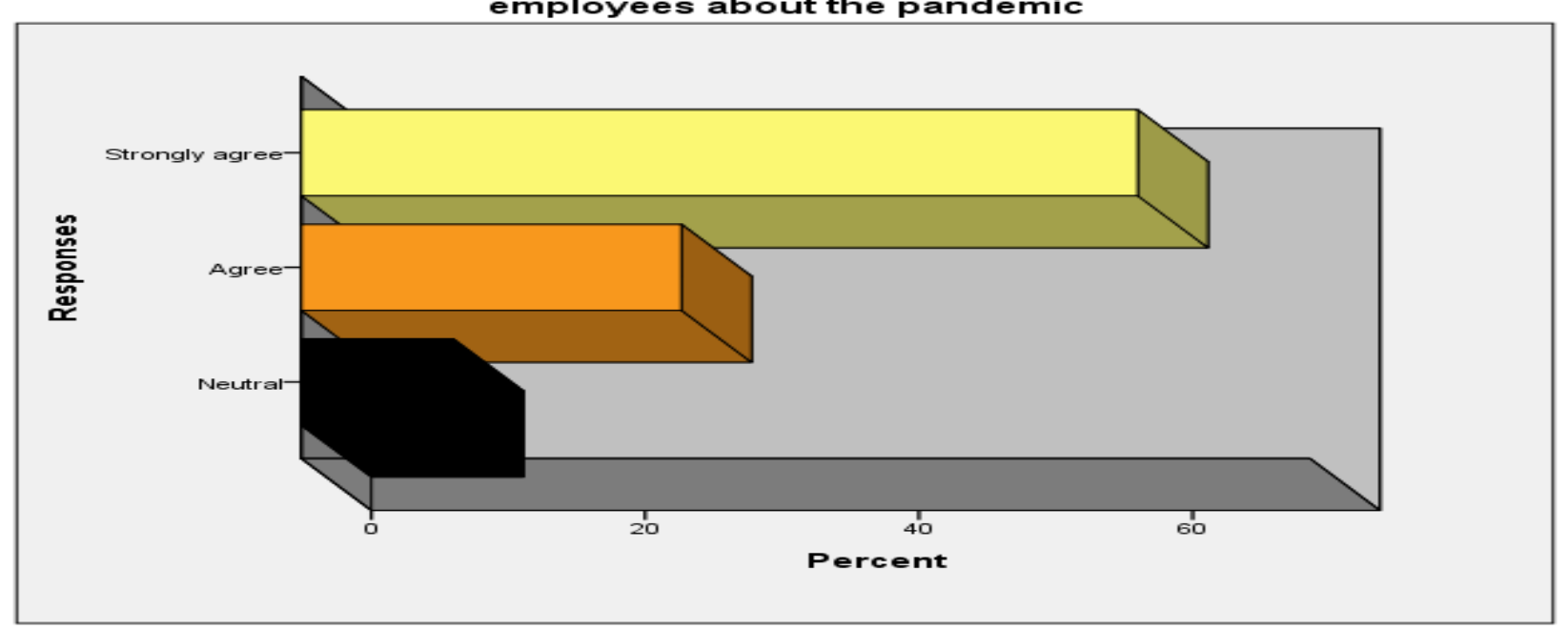

Figure 3

It is popularly said that if you are not informed, you are deformed. Knowledge and awareness of Covid-19 transmission process, symptoms, effect and possible prevention measures are paramount to reduce or possibly avoid the spread. Employees are the most important asset of every corporate organization; this assertion is assured as employees are involved in the production or service process regardless of whether human labour or machines are utilized in the system. The first case of Coronavirus in Nigeria was reported on $27^{\text {th }}$ February 2020. The constant increase in the number of cases was a red flag to organization HRs to initiate strategic modus to operate in the pandemic crisis. $61.1 \%$ of the respondents strongly agreed, $27.8 \%$ agreed while $11.1 \%$ were neutral on the management adequate communication to the employees about the coronavirus and its implications on the organization. 
Table 1: Executive board/top management response to the pandemic crisis

\begin{tabular}{|c|c|c|c|}
\hline & $\mathrm{N}$ & Mean & $\begin{array}{l}\text { Std. } \\
\text { Deviation }\end{array}$ \\
\hline $\begin{array}{l}\text { Overall, I am pleased with how my organization handles the } \\
\text { pandemic situation }\end{array}$ & 221 & 1.6471 & .58957 \\
\hline My work tasks and duties have been changed & 234 & .3889 & .48854 \\
\hline My working hours have been reduced & 234 & .3333 & .47242 \\
\hline I experience work-life balance & 195 & .5333 & .50017 \\
\hline $\begin{array}{l}\text { Employee experience and/or HRM practices have been a } \\
\text { strategic focus area for my organization during this } \\
\text { pandemic crisis }\end{array}$ & 208 & .8750 & .33152 \\
\hline $\begin{array}{l}\text { The top management has encouraged HRM practices to } \\
\text { improve employees wellbeing }\end{array}$ & 234 & .7222 & .44886 \\
\hline $\begin{array}{l}\text { Have your organization changed the policy regarding remote } \\
\text { working because of the Covid-19 pandemic situation }\end{array}$ & 234 & .4444 & .49797 \\
\hline Valid N (listwise) & 169 & & \\
\hline
\end{tabular}

In critical times, organizations response to situations weighs the level of care and concern channelled to the wellbeing of the staff. The actions taken by executive board/top management is appreciated by the respondents in both public and private sector with a few dissatisfactions from employees in public organizations. Employees enjoy work-life balance during the pandemic crisis. Work and life in the new normal require strategic adjustments and modificationto allowed effectiveness. Remote working has been introduced to allow employees to work from home and still be able to attend to family needs and child care. Remote working is new to most of the organization, with several organizations lacking in the know-how and necessary facilities to promote remote working. Thus, the challenge and need to train staff on how to utilize new technologies and tools which will aid working from home becomes paramount. 


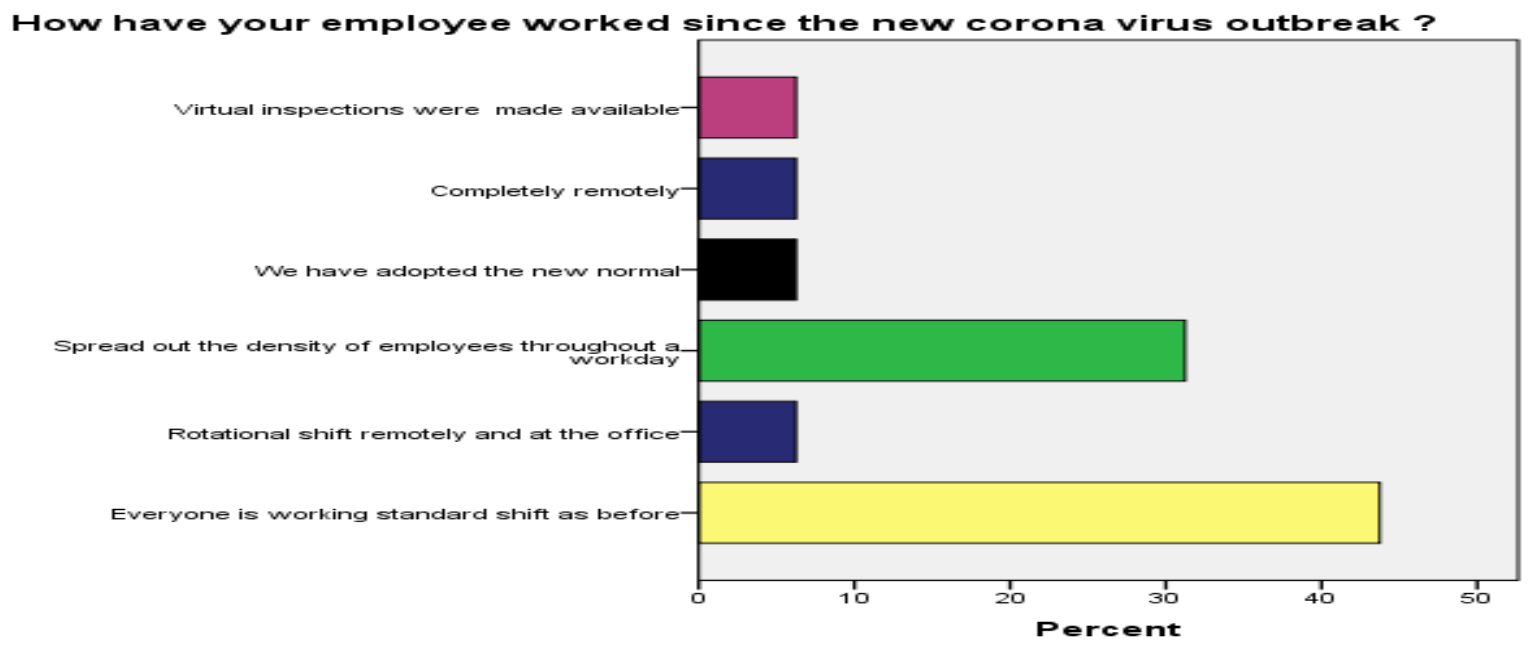

Figure 4

The Covid 19 pandemic has necessitated the implementation of telecommuting for both large and small organizations. Adhering to the Covid 19 precautions, Multi Corporation has reduced density of employees and encouraged work from home for certain positions. Most of the organizations have maintained their normal standard shift before the pandemic. Companies that could adopt complete remote working initiated it in the first phase of the total lockdown in major cities of Nigeria. Visual platforms were also used to monitor projects and employees.

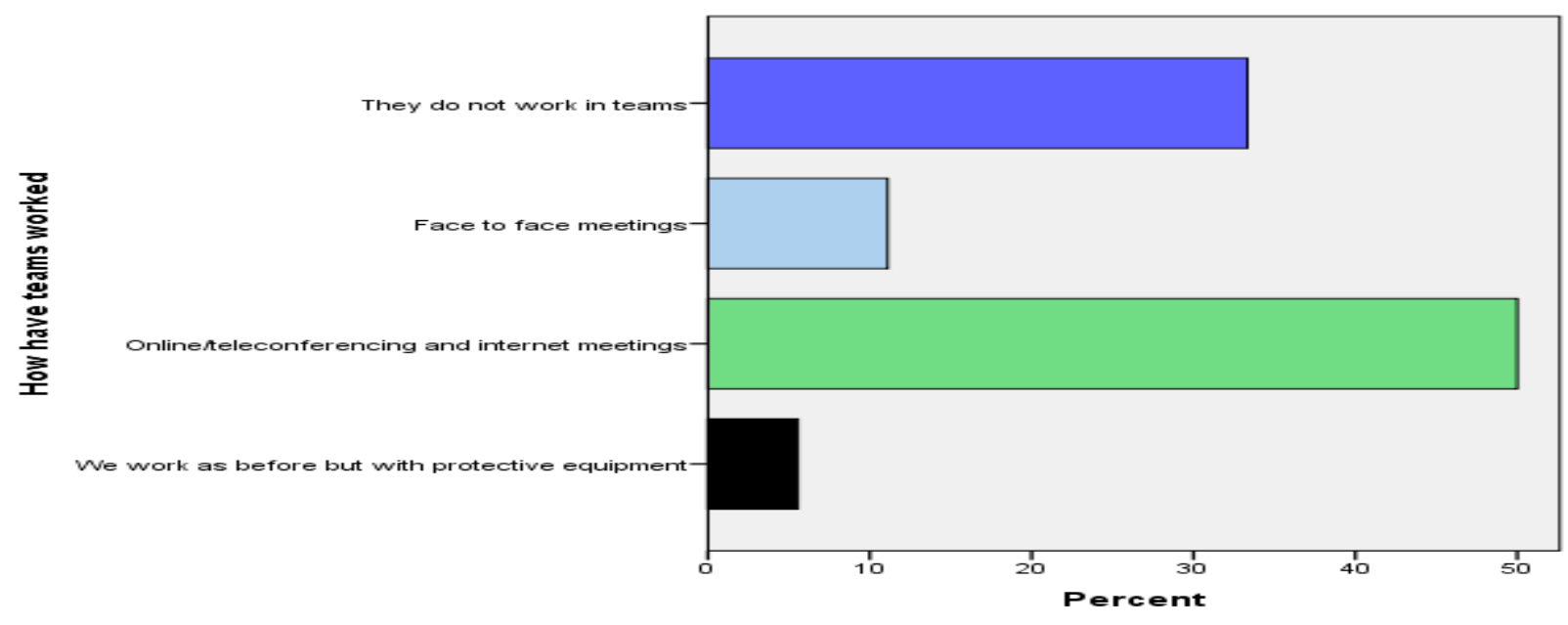

Figure 5

Social distancing imposed by the government to curtail the spread of Covid 19, altered the spirit of face to face teamwork in most of the organizations. Though not in totality, few organizations especially in the health sector could work in teams but with protective equipment. Teleconferencing was mostly used for team communication. 


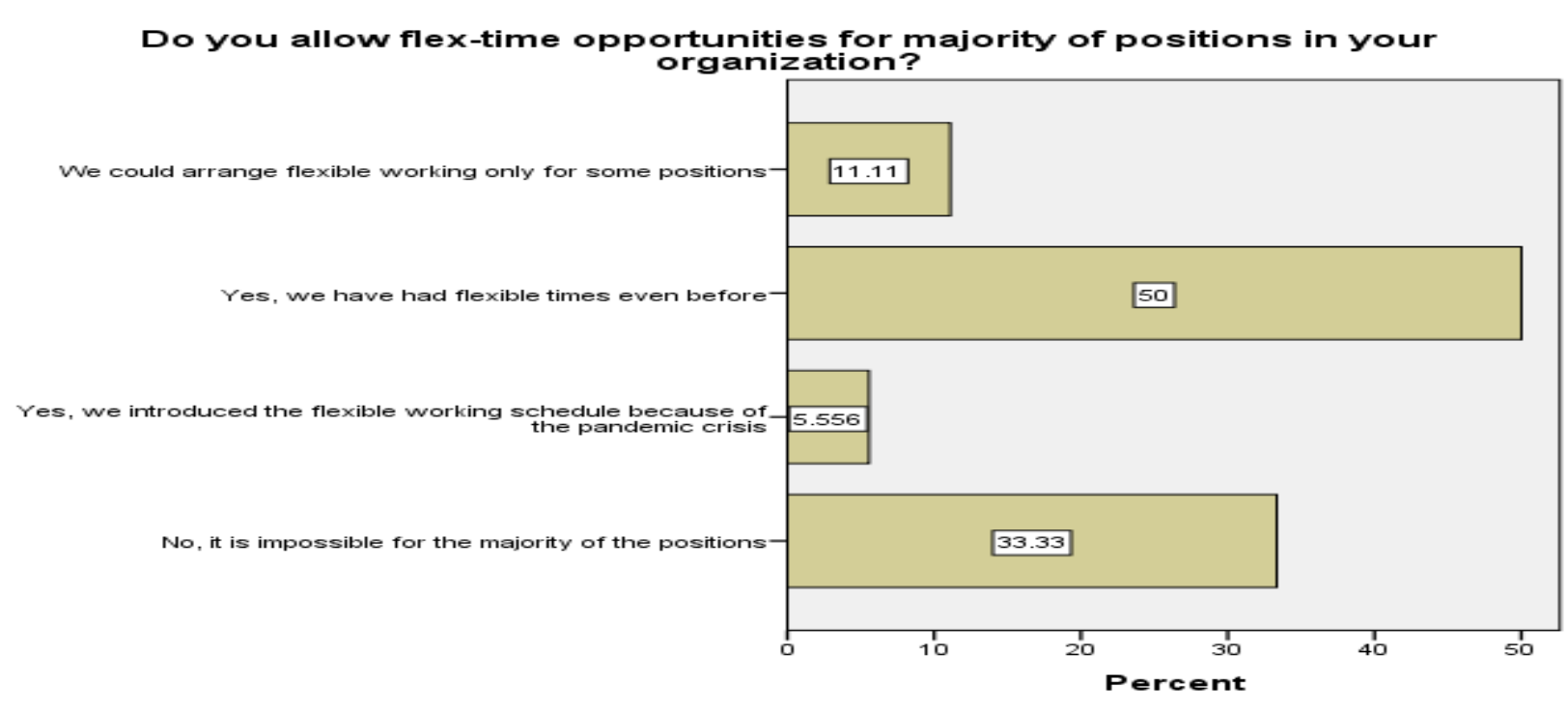

Figure 6

Reducing employee density was/is necessary for the new normal. Flextime has been in use before the pandemic in most of the organizations. Several organizations could not initiate flex time for the majority of the positions. Considering the Nigerian working environment and the gravity of Covid 19 on business operations, only a few organizations initiated flex time as a result of the pandemic crisis.

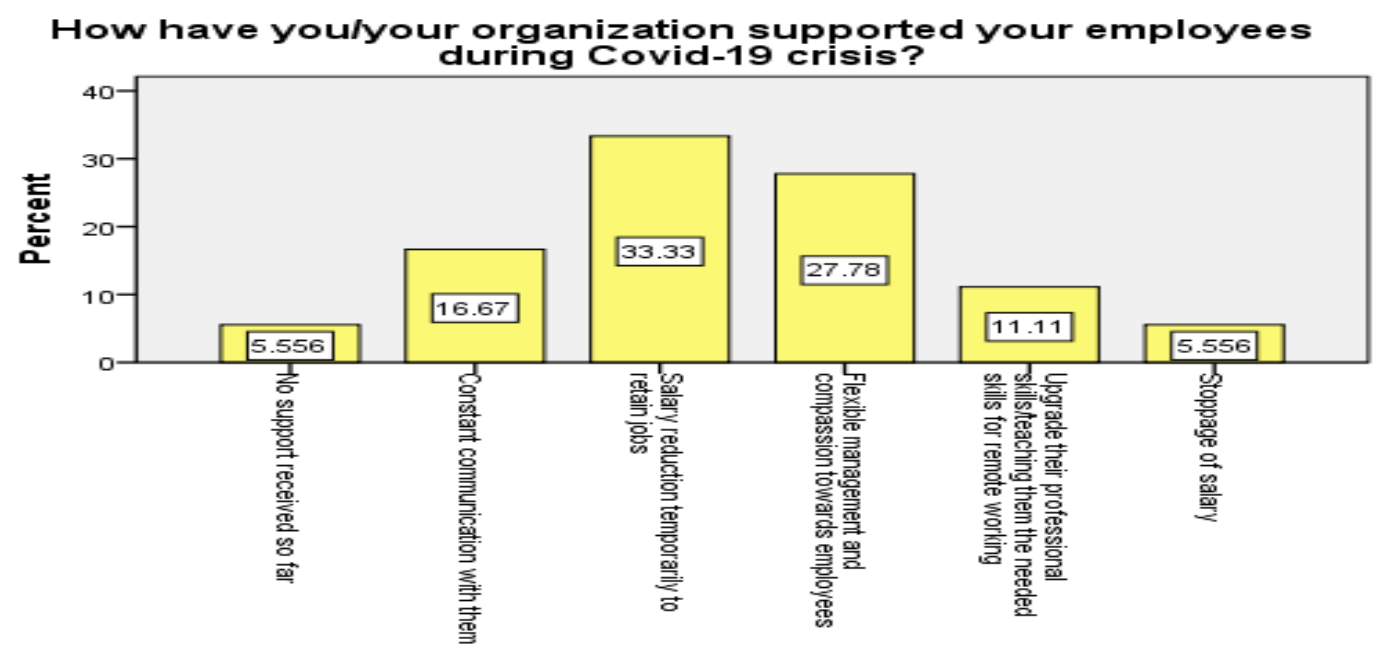

\section{Figure 7}

Different organizations took separate steps to respond to the pandemic effect on employees and the organization's sustainability. Salaries of employees were either stopped or reduced by different percentages to maintain staff strength. Employees were to be IT compliant and upgraded with professional skills to aid them in remote working. While employees indicated that constant communication from management, others show no support was received from top management. 


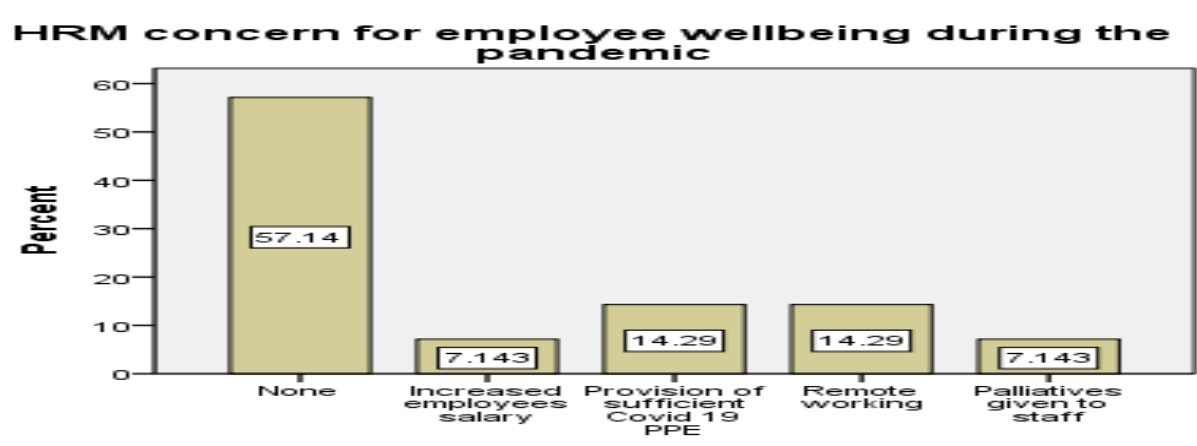

Human resource manager's role has become much more dynamic than before. The pandemic has created a more complex business environment, needing strategic implementations to sustain organizations and manage an effective team (staff) in times of uncertainty. More than half of the respondents indicated that they received no specific support from HRM during the pandemic crisis. Increased salaries were also used to motivate the employees while palliatives in several forms were given to staff.

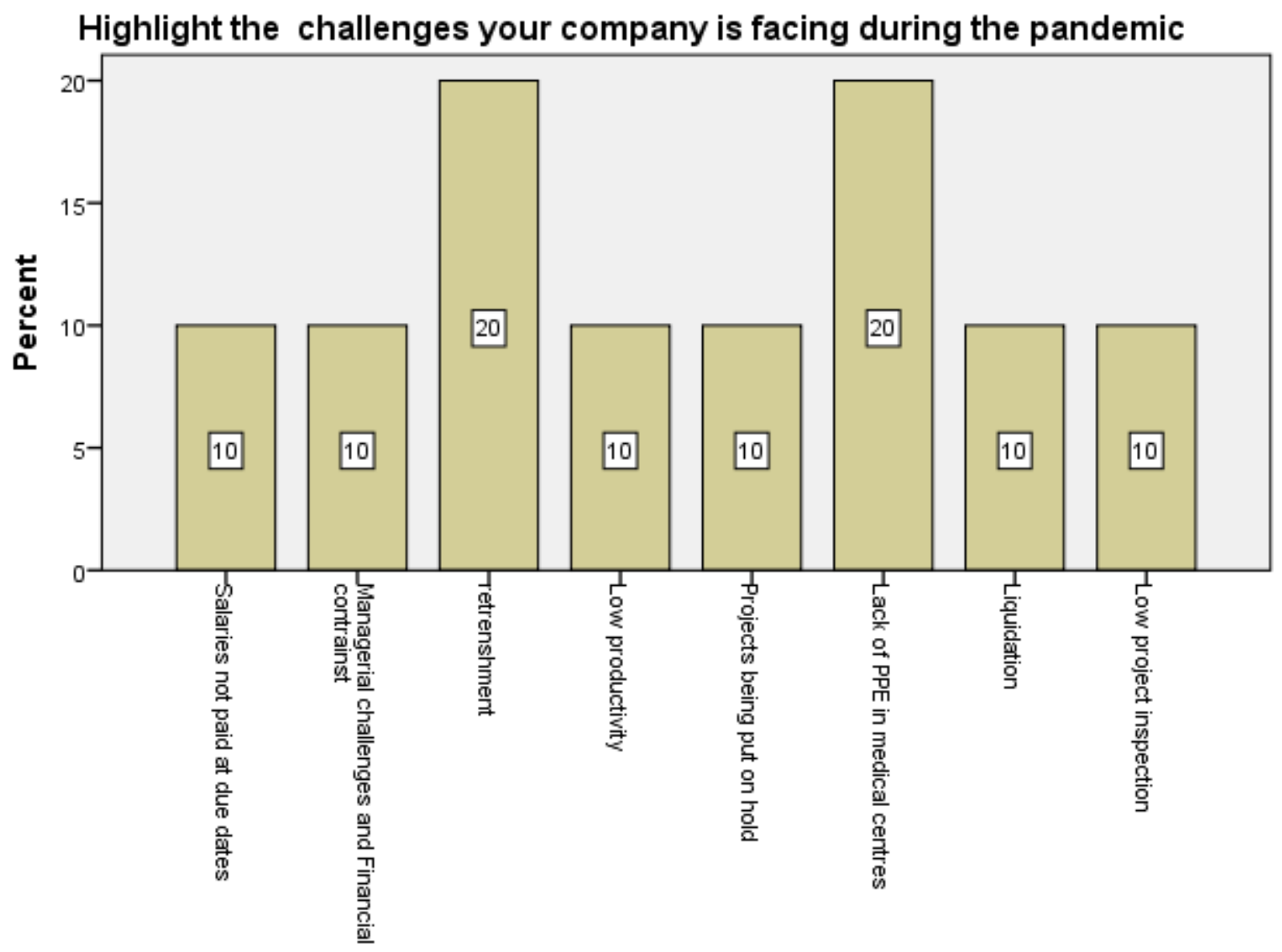


The pandemic crisis has altered the normal way of business operations and introduced a new normal. Covid 19 has posed several challenges to organizations globally. The survey reveals low productivity especially for manufacturing companies, retrenchment an organization that could not maintain the same staff number and default in payment of earned salaries. So many SMEs winded up as a result of the pandemic crisis while $20 \%$ of health companies complained of lack of personal protective equipment (PPE), low project inspection.

\section{Conclusions/ Recommendations}

The Covid-19 pandemic has presented serious mental, physical and financial complications to employees. The shock of the pandemic is such that every spectrum of both human and economic activity is severely impeded. For sustainability, organizations now have to rely more than ever on their HR department as a corporate strategy to ensure their workforce feel safe as possible during this unprecedented and unpredictable time. HR manager playsa key role during the pandemic as many businesses are struggling to keep their doors open and finding ways to keep their employees and customers safe, comfortable and productive.

This study made use of questionnaire and interview to better structure the issues associated with the current pandemic and HRM. The data was interpreted and asserts were drawn from the opinion of the respondents. The study aimed to heighten the relevance of strategic human resource management in the Covid-19 pandemic business environment.

The study concludes that employees' performance is not significantly affected by the pandemic as many of the companies maintain a normal standard shift for its workforce. The acceleration of digitalization of processes made it possible for these companies to overcome the challenges posed by the pandemic. However, productivity especially in the manufacturing industry is low due to the absence of employees needed for physical operation and other core aspects of production. The study also concludes that employees enjoyed work-place balance. Finally, the study concludes that organizations were faced with severe challenges such retrenchment of workforce especially in the manufacturing industry, lack of PPE in medical centres and liquidation of some businesses as a result of zero productivity and profitability.

The study recommends among others the need to develop HR as employees need to develop skills such as information technology which will aid them in the digitalization of processes. More so, there should be more incentive put in place to support employees in difficult times and finally, organizations should be more interested in their employees' wellbeing by proving and implementing the necessary equipment that will minimize the exposure of the employee to a deadly virus such as covid-19. 


\section{References}

First Case of Corona Virus Disease Confirmed in Nigeria. Nigeria Centre for Disease Control. 28 February 2020. Retrieved 21 January 2021.

Iza G. (2020). Influence of covid-19 crisis on Human Resource Management and Companies Response: The Expert study. International Journal of Management Science and Business Administration. 6 (6), 15-24

Iza, G. (2020). Challenges HR managers are facing due to Covid-19 and coming strategies: perspective from Georgia Archives of Business Research, 8(11)1-18

Kevin, M. K. (2020). Covid-19 and workplace implications, issues, and insights for future research and action; Harvard Business School working-paper 20-137

Maclean, R \&Dahir, A. L.f (28 February 2020). "Nigeria Responds to First Coronavirus Case in Sub-Saharan Africa". The New York Times. Retrieved 21 January 2021.

Mayer, B. (2020).Managing HR through covid-19: A practical guide for multinational employers (mayerbrown.com)

Nigeria records second case of Coronavirus. P.M. News. 9 March 2020. Retrieved 21 January 2021.

NKF. (2020). Evolution of the workplace post-Covid-19 (newmarknewnormal@nkff.com)

OECD. (2020). Guidelines for recipient country investment policies relating to national security, Paris Retrieved from https://www.oecd/daf/inv/investment-policy/43384486.pdf 